\title{
CONFABULAÇÃO SOBRE ANÁLISE DE CONTEÚDO COMO TÉCNICA DE ANÁLISE DA HISTÓRIA ORAL
}

\section{ARTIGO DE REVISÃO}

RIBEIRO, Vagno Batista ${ }^{1}$

PURIFICAÇÃO, Marcelo Máximo ${ }^{2}$

CATARINO, Elisângela Maura ${ }^{3}$

RIBEIRO, Vagno Batista. PURIFICAÇÃO, Marcelo Máximo. CATARINO, Elisângela Maura. Confabulação sobre Análise de Conteúdo como Técnica de Análise da História Oral. Revista Científica Multidisciplinar Núcleo do Conhecimento. Ano 05, Ed. 01, Vol. 02, pp. 57-68. Janeiro de 2020. ISSN: 2448-0959, Link de acesso: https://www.nucleodoconhecimento.com.br/historia/analise-de-conteudo

${ }^{1}$ Mestre em Teologia - Educação Comunitária Infância e Juventude pela Escola Superior de Teologia - EST. Doutorando em História pela Universidade do Vale do Rio dos Sinos - UNISINOS.

2 Pós-doutor em Educação pela Universidade de Coimbra. Doutor em Ciências da Religião pela Pontifícia Universidade Católica de Goiás - PUC-Goiás. Professor Titular C-II, no UNFIMES/GO, Professor Permanente no Programa de Pós-Graduação em Educação da Faculdade de Inhumas (PPGEdu/FACMAIS) e Professor Permanente no Mestrado Profissional em Intervenção Educativa e Social - MPIES da Universidade do Estado da Bahia - UNEB.

${ }^{3}$ Doutora em Ciências da Religião pela Pontifícia Universidade Católica de Goiás PUC-Goiás. Em Estágio Pós-doutoral pela Escola Superior de Educação de Coimbra - ESEC. Professora Titular C-II no UNIFIMES/FIMES. 


\section{RESUMO}

Na obra "Análise de conteúdo", Laurence Bardin aborda aspectos da construção da pesquisa científica que vão desde o levantamento histórico acerca de técnicas e análises utilizadas na análise do conteúdo ao longo dos anos, até a proposta de um método de investigação que, de fato, possa ser operacionalizado pelos diversos pesquisadores das ciências humanas, quais sejam psicólogos, sociólogos, linguistas, jornalistas e historiadores. No que se refere aos historiadores, a análise do conteúdo e a análise documental propostas por Laurence Bardin podem proporcionar importantes reflexões para a construção da pesquisa histórica. Nesse sentido, o presente artigo busca refletir sobre as possibilidades de discussões e metodologias que as considerações da referida autora proporcionam aos pesquisadores que se utilizaram (utilizam) de fontes da chamada História Oral, na construção da sua narrativa histórica. Diante desses objetivos, optamos por apresentar inicialmente as considerações da autora em "Análise de conteúdo". Posteriormente, apontamos as técnicas de análises presentes na obra citada que podem ser articuladas à análise da metodologia da História Oral. Por fim, colocamos a relevância dessas trajetórias de pesquisa para a construção da narrativa histórica que é subsidiada por fontes orais.

Palavras-chave: Pesquisa histórica, técnicas, fontes, história oral.

\section{INTRODUÇÃO}

Como constituição do saber feita pelo estudioso, pelo cientista, pelo filósofo, o conhecimento científico é resultante da reflexão e da pesquisa sistemática que leva a novos conhecimentos. Nessa percepção, a ciência é o resultado da elaboração mental, da reflexão, do estabelecimento de relações, da observação de causas, de consequências, de continuidades, de contiguidades, de oposições[4]. Pode-se, portanto, identificar a construção do conhecimento como a constituição dos saberes que resulta da investigação filosófico-científica, por um lado, e da "construção" do conhecimento no modo pelo qual cada um apreende a informação e aprende algum conteúdo, por outro. Nesse último caso, o sujeito não propriamente "constrói" o saber, somente apropria-se de um conhecimento já estabelecido"[5] 
No que se refere ao desenvolvimento da pesquisa histórica infere-se que esse sempre depende da utilização das fontes, do aprimoramento da pesquisa, dos métodos e da capacidade interpretativa do historiador[6]. Nesse sentido, além do método de pesquisa, as fontes configuram-se como parte primordial da produção do conhecimento histórico.

Sobre a relação metodologia-fontes para a construção da pesquisa histórica, especialmente quando tratamos das fontes orais, as considerações de Laurence Bardin em Análise do Conteúdo, psicóloga e educadora que aplicou técnicas sobre como analisar o conteúdo na investigação psicossociológica e no estudo das comunicações de massas ao longo da década de 1950 na França, são fundamentais. Isso posto, propõe-se neste artigo abordar como a análise do conteúdo e a análise documental propostas por Laurence Bardin podem proporcionar importantes reflexões para a construção da pesquisa histórica.

\section{ANÁLISE DO CONTEÚDO: "O RIGOR DA OBJETIVIDADE E A FECUNDIDADE DA SUBJETIVIDADE'[7]}

No livro "Análise do Conteúdo", Laurence Bardin organiza as suas ideias em quatro partes diferentes. A primeira se refere à história e teoria, em que a autora apresenta uma perspectiva histórica da análise do conteúdo. $\mathrm{Na}$ segunda parte, há considerações sobre a etapa prática da análise, na qual Laurence Bardin aborda análises de entrevistas, de comunicação de massa, de questões abertas e de testes.

Na próxima seção observamos as discussões sobre os métodos de análise, em que são abordadas a organização, a codificação, a categorização, a inferência e a informatização das análises. Por último, temos as técnicas de análise, análise categorial, de avaliação, de enunciação, proposicional do discurso, de expressão e das relações. A partir dessa divisão, a referida autora elabora um verdadeiro guia, um manual, como ela mesma se refere[8], no qual organiza a análise do conteúdo em três fases: 1) Pré-análise, 2) Exploração do material e 3) Tratamento dos resultados, inferência e interpretação. 
$\mathrm{Na}$ chamada pré-análise, cabe ao pesquisador organizar o material a ser analisado com o objetivo de torná-lo operacional, sistematizando as ideias iniciais do tema que pretende pesquisar. De acordo com a autora, nessa primeira fase elabora-se uma organização do que realmente será pesquisado. Para tanto, estabelecem-se quatro momentos: incialmente deve-se realizar uma leitura flutuante, que é o estabelecimento do contato com os documentos para a coleta de dados, momento em que se começa a conhecer o texto; depois há a seleção dos documentos, que consiste na demarcação do que será analisado; posteriormente, a formulação das hipóteses e dos objetivos; e, por fim, faz-se a referenciação dos índices e elaboração de indicadores, que envolve a determinação de indicadores por meio de recortes de texto nos documentos de análise[9].

A segunda fase consiste na etapa da exploração do material, quando será realizada a análise do material com a definição de categorias, os chamados sistemas de codificação, e a identificação das unidades de registro e das unidades de contexto nos documentos. Essa fase consiste numa etapa importante, posto que é possível analisarmos a riqueza das interpretações e inferências. Nessa etapa observa-se a descrição analítica, onde há a análise do corpus teórico e/ou documental, isto é, qualquer material textual coletado submetido a um estudo aprofundado, orientado pelas hipóteses e referenciais teóricos. Dessa forma, a codificação, a classificação e a categorização são etapas básicas desta fase.

Após esses dois passos iniciais, Laurence Bardin propõe a terceira fase, que se refere ao tratamento dos resultados obtidos e a interpretação do pesquisador/ leitor sobre o conteúdo. Essa etapa, de acordo com a autora, é o momento da intuição, da análise reflexiva e crítica, em que são destacadas as informações, resultando nas interpretações inferenciais.[10] Na quarta e última parte da obra em análise, a referida autora propõe como discussão central a inferência. Segundo ela, a inferência como técnica de tratamento de resultados é orientada por diversos polos de comunicação, qual seja emissor, receptor, mensagem e canal.

No que diz respeito aos objetivos elencados no presente trabalho, a terceira e quarta parte são mais importantes. Isso porque nessas duas seções, Laurence Bardin 
aprofunda-se na questão do método e das técnicas. Segundo a autora, para que haja uma aplicabilidade coerente do método de acordo com os pressupostos de uma interpretação das mensagens e dos enunciados, a análise de conteúdo deve ter como ponto de partida uma organização.

Une-se a essas técnicas a própria construção do conhecimento científico, que acaba oscilando entre dois polos que envolvem a investigação científica: o rigor da objetividade, da cientificidade reflexo da própria construção desse tipo de conhecimento, e a riqueza da subjetividade, da autonomia que o autor possui no âmbito da sua produção. A técnica passa a ter como objetivo ultrapassar o senso comum do subjetivismo do autor e alcançar o rigor científico necessário, mas não com rigidez, que segundo Laurence Bardin, não condiz mais com a ciência desenvolvida nos tempos atuais.

Nessa perspectiva, aborda o contexto da década de 1940/ 1950, em que o conhecimento científico estava pautado em discussões que diziam respeito à validade das técnicas qualie quantitativas, uma em detrimento da outra. Ao se colocar em meio a esse debate, a referida autora entende que ambos os tipos de técnicas podem ser utilizados para a realização da análise do conteúdo, e que não eliminam uma a outra.

Partindo dessas considerações, e amparado nos nossos objetivos, as propostas de Laurence Bardin nos levam a refletir sobre as técnicas de análise de conteúdo caracterizadas como qualitativas. Conforme sugere, "Na análise qualitativa é a presença ou a ausência de uma dada característica de conteúdo ou de um conjunto de características num determinado fragmento de mensagem que é tomado em consideração".[11]

Sendo assim, na análise qualitativa temos, enquanto conjunto de técnicas de análise, uma ancoragem consistente no rigor metodológico, com uma organização propícia à compreensão apurada do método, ao mesmo tempo em que possibilita a produção de sentidos e significados na diversidade de textos e documentos do mundo acadêmico. 
Nos últimos anos, a produção historiográfica no Brasil tem empreendido diversos estudos de abordagem qualitativa em trabalhos que são fundamentados por memórias que emergem a partir da história de vida dos sujeitos.[12] Essa característica demonstra ser resultado de uma aproximação entre as ciências humanas e as de natureza que tem se preocupado em contextualizar, cultural e socialmente, as pessoas, grupos e suas práticas, tendo como foco a apreensão dos significados, motivações, emoções e valores para elucidar atitudes, comportamentos e práticas sociais.

O campo de produção historiográfica que tem se voltado mais especificamente para a história oral se refere aos estudos da história e da memória de um indivíduo, povo, grupo e/ou movimento social, sendo utilizado atualmente por diversos historiadores, psicólogos, sociólogos, antropólogos, etc. Como concepção, temos que o uso da metodologia da História Oral consiste em narrativas e relatos sobre um fenômeno, um acontecimento ou um período de tempo, recolhidos por meio de estudo documental, depoimentos e entrevistas (gravadas em áudio e/ou vídeo), as quais podem ser trabalhadas por meio de diversos procedimentos e técnicas.

Sobre esse aspecto, a História Oral, enquanto uma união de método, fonte e técnica, embora também seja considerada por muitos historiadores como campo científico, pode ser colocada no âmbito das técnicas de análise de conteúdo qualitativas, conforme coloca Laurence Bardin. Além disso, conforme sugere Verena Alberti[13], a História Oral é um método de pesquisa que privilegia o acesso a informações diretamente das fontes testemunhais; produzindo fonte, que são os depoimentos, as narrativas, as quais são colhidas através da técnica de entrevista.

Dessa maneira, é possível utilizarmos a metodologia da História Oral, amparados no que Laurence Bardin sugere para as análises que se configuram no âmbito das pesquisas qualitativas, posto que assim poderemos captar o entendimento das dimensões da existência como os processos relacionais, subjetivos históricos e seus contextos sociais. 
Como a história oral trabalha com as lembranças e com os esquecimentos evocados ou silenciados pelos sujeitos no momento da entrevista, reportando-se acontecimentos passados, essas técnicas nos ajudam a entender tais sujeitos, na forma que ressignificam os acontecimentos que experienciaram. Empregada e estudada por vários autores tanto no Brasil como em outros países, a história oral apresenta entendimentos diversos, especialmente por pertencer a campos de estudos e pesquisas que trabalham, sobretudo, com as relações entre história e memória.

\section{HISTÓRIA, MEMÓRIA E A METODOLOGIA DA HISTÓRIA ORAL}

A partir da leitura de textos como: Memória[14], Memória funcional e memória cumulativa- dois modos de recordação[15], Entre memória e história. A problemática dos lugares[16] e Memória Coletiva e memória histórica[17] é viável discutimos as características próprias de cada um e as aproximações e distinções existentes entre o campo da História e o da Memória. Além disso, a partir da "demarcação" de suas diferenças, é possível também sugerirmos como a ciência histórica pode utilizar a memória como ferramenta para a construção da sua narrativa.

Umas das primeiras questões que essas leituras sugerem são os "permanentes presentes" em que as culturas contemporâneas estão inseridas. Nos textos mencionados acima, com maior ou menor ênfase, estão presentes a forma como o movimento histórico no ritmo acelerado das tecnologias - "a era cibernética" - aborda a memória (ou as memórias) dos grupos, especialmente a memória coletiva.

Os autores conseguem perceber, mesmo em contextos anteriores ao nosso, como essa contínua aceleração do tempo atravessa e mexe com a memória dos grupos; contornando-a e em até certo ponto alterando a maneira como pode ser conservada e repassada para os descendentes. Para o entendimento desse movimento, cabe apresentarmos como cada um dos autores entendem a memória.

Jacques Le Goff, em Memória apresenta sistematicamente cinco "fases" que a memória coletiva passa ao longo do tempo dentro das sociedades. Segundo o autor, "para valorizar melhor as relações entre a memória e a história é necessário evocar 
separadamente a memória"[18] Nesse sentido, o autor entende que a memória coletiva está inserida dentro das "grandes questões"[19] das sociedades já desenvolvidas e outras em processos de desenvolvimento, dos grupos dominantes e dominados que lutam e, ao mesmo tempo, compartilham as necessidades de sobrevivência das suas características socioculturais.

Com o decorrer das etapas históricas, pode-se perceber a importância da função que a memória coletiva desempenha para com os agrupamentos. A memória é ilustrada por Le Goff pelas cinco etapas seguintes: a memória étnica nas sociedades sem escrita, o desenvolvimento da memória, passando da oralidade à escrita, a memória medieval, em que há um equilíbrio entre a oralidade e a escrita, os progressos da memória escrita do século XVI aos nossos dias e os desenvolvimentos atuais da memória.

Aleida Assmann, por sua vez, concordando com Le Goff sobre os aspectos da memória histórica no texto: Memória funcional e memória cumulativa - Dois modos da recordação - acrescenta o quão insatisfatório é o distanciamento "brusco" entre História e Memória bem como o sentido contrário: o nivelamento das mesmas. Como "terceira via", a autora aponta para a compreensão do que seria a "memória funcional" e a "cumulativa" como formas de recordação que se complementam.

À primeira liga-se a singularidade e a continuidade de um grupo, que existe sempre no plural e acaba por obscurecer ostensivamente as mudanças. A "memória histórica", por outro lado, não tem função identitária, constrói molduras integradoras para muitas narrativas e existe no singular e é nas mudanças que se especializa.

Dessa maneira, propõe que em substituição a "memória habitada" e "inabitada" utilizemos "memória funcional" para a primeira (a Memória) e "memória cumulativa" para a segunda (a História). No que se refere à "memória funcional", Assmann considera que as suas características principais estão ligadas ao grupo, à seletividade, à vinculação a valores e à orientação ao futuro. Com a "memória cumulativa”, por sua vez, por se tratar de uma memória de segunda ordem - a 
memória das memórias - é possível a recuperação de vestígios e acervos que "ficaram sem dono"; oferecendo, assim, novas possibilidades a "memória funcional".

À medida que a "memória cumulativa" vincula-se a anseios políticos ou delineia-se a identidades distintas e se recorda muito mais do que se necessita, torna-se compreensível "as bordas da "memória funcional"”[20], que, segundo a autora, podem ser utilizadas por pelo menos três formas: legitimação, deslegitimação e distinção. Assim, o mais viável é que ambas estejam juntas, pois pertencem a culturas que se autonomizam e, ao passo que se colocam à pluralidade de sua diferença interior, se abrem para sua diferença exterior.

A história e a memória para Pierre Nora evocam o mesmo tempo, o passado. Entretanto, apesar do possuírem o mesmo substrato, ambas não se confundem. Enquanto a primeira é caracterizada pelo distanciamento, pela problematização, crítica e reflexão dos fatos, as ocorrências sociais dos grupos, a memória, que não existe mais em si, é o que está vivo, a vivência. E com a contínua aceleração do tempo, há a necessidade de assegurar traços e vestígios da "vivência" das sociedades pretéritas.

Assim, Pierre Nora admite em Entre memória e história. A problemática dos lugares que através da aceleração dos tempos não há mais existência da memória, mas sim lugares de memória. Para o autor, os "lugares de memória" são, em primeiro lugar, lugares de três acepções: são lugares materiais, onde a memória social se ancora e pode ser apreendida pelos sentidos, são lugares funcionais, porque tem ou adquiriram a função de alicerçar memórias coletivas e também são lugares simbólicos onde essa memória coletiva, portanto, são lugares carregados de memória.

Também Para Maurice Halbwachs, especialmente em Memória Coletiva e memória histórica, a memória coletiva não pode se confundir com a história. Segundo o autor, a história tem início onde a memória encerra-se, e essa tem fim quando acaba seu principal suporte: o grupo. Isso porque, para o mesmo autor, a memória individual está sempre remetida à participação dos indivíduos em grupos, a memória coletiva, pois 
apesar de ter suas lembranças pessoais, os indivíduos estão sempre interagindo com os grupos do qual fazem parte.

Dessa forma, a memória coletiva tem a importante função de fazer com que as pessoas expressem a sensação de pertencimento a um grupo. Ela garante um sentimento de identidade ligado não só ao campo histórico, mas também às representações e aos símbolos. No que diz respeito às relações de história e memória, esses autores comungam da ideia de que os dois campos são diferentes, mas que interagem intensamente dentro da escrita histórica.

Assim o é porque a história pode se utilizar da memória para a construção da sua narrativa. À história, enquanto campo científico, estão aliadas a crítica e a "modulação" da memória, dos aspectos que são retomados pelos grupos sociais periodicamente e que dizem muito sobre a sua identidade. Utilizar-se, portanto, da memória, pode servir de ancoradouro a partir do qual se descreverão e se analisarão os aportes que a história oral pode fornecer aos estudos históricos.

\section{CONSIDERAÇÕES FINAIS}

Conforme abordamos, os historiadores que se utilizam de fontes orais para escrever as suas narrativas históricas geralmente recorrem às relações de História e Memória. No entanto, ainda é necessário dar maior profundidade às reflexões propostas por esses autores para que haja melhor fundamentação nas práticas desenvolvidas. Nesse sentido, a partir das considerações de Laurence Bardin em Análise e Conteúdo, especialmente ao que sugere para a análise feita através de técnicas qualitativas, é possível transformar essa realidade e desenvolver melhores pesquisas sobre a memória, lembranças e esquecimentos, dos indivíduos.

Segundo Laurence Bardin apresenta, a pesquisa científica não deve ser vista como uma ação neutra, pois sempre está conectada a uma perspectiva e uma visão de mundo. Nesse sentido, a pesquisa carrega em si responsabilidades e é parte do processo social em que se insere. Sendo assim, a partir o método da história oral e o 
auxílio das técnicas de características qualitativas na análise das entrevistas, podemos realizar pesquisas de modo ético e interativo.

Por outro lado, podemos chegar à identificação de possíveis injustiças históricas e sociais das quais as pessoas são vítimas, a partir da ocultação e do silenciamento de indivíduos e/ou grupos. Assim, histórias particulares podem ser inseridas numa dimensão mais ampla que as vinculem a experiências similares e a outros espaços sociais e políticos. A aplicação dessas técnicas na leitura de fontes orais pode igualmente favorecer a expressão de pessoas e grupos silenciados pela história oficial, permitindo a construção de novas perspectivas e possibilidades de mudanças.

Ela fornece, portanto, as técnicas qualitativas de análise de conteúdo podem fortalecer a pesquisa que se utiliza da História Oral tanto pelo rigor como pela participação das pessoas e grupos envolvidos nos estudos do campo. Produzir história com essas técnicas, portanto, torna-se fundamental para que narrativas minoritárias - e que se produzem nas próprias margens - possam surgir e colaborar para a desnaturalização das narrativas hegemônicas.

\section{REFERÊNCIAS}

ALBERTI, Verena. Manual de História Oral. Rio de Janeiro: FGV, 2004.

ASSMANN, Aleida. Memória funcional e memória cumulativa - Dois modos da recordação. In: Espaços de Recordação: formas e transformações de memória cultural. Editora Unicamp: Campinas, 2011.

BARDIN, L. Análise de conteúdo. Lisboa: Edições 70, 1977. Análise de conteúdo. Lisboa: Edições 70, 1997.

BOURDIEU, P. A ilusão biográfica. In: AMADO, J.; FERREIRA, M. M. (Coord.). Usos e abusos da história oral. Rio de Janeiro: Ed. FGV, 2000. p. 183-191

HALBWACHS, M. A memória coletiva. São Paulo: Vértice, 1990. 
HUSSERL, E. Méditations cartésiennes. Tr. de l'allemand par Gabrielle Peiffer et Emmanuel Lévinas. Paris: J. Vrin, 1980.

LE GOFF, Jacques. Memória In: História e memória. Campinas: Ed. Unicamp, 1994.

POLLAK, M. Memória, esquecimento, silêncio. In: Estudos Históricos, v. 2, n. 3, p. 315, 1989.

Memória e identidade social. In: Estudos Históricos, v. 5, n. 10, p. 200-212, 1992.

NORA, Pierre. Entre Memória e História: a problemática dos lugares, In: Projeto história: Revista do programa de estudos pós- graduados em história e do departamento de história da PUC- SP. São Paulo: PUC, 1981.

RODRIGUES, J. H. Teoria da História do Brasil: introdução metodológica. $5^{\underline{a}}$ ed. São Paulo: Nacional, 1978

WERNECK, Vera Rudge. Sobre o processo de construção do conhecimento: O papel do ensino e da pesquisa In: Ensaio: aval. pol. públ. Educ., Rio de Janeiro, v.14, n.51, p. 173-196, abr./jun. 2006, p.176.

\section{APÊNDICE - REFERÊNCIAS DE NOTA DE RODAPÉ}

4. HUSSERL (1980) apud WERNECK, 2006.

5. Ibid.

6. RODRIGUES, 1978.

7. BARDIN, L. Análise de conteúdo. Lisboa: Edições 70, 1997, p. 9.

8. BARDIN, 1977, p. 9.

9. Ibid. 
10. BARDIN, 1977, p. 39.

11. BARDIN, 1977, p.21.

12. Sobre estudos que refletem sobre questões da Memória, seja individual ou coletiva, e a sua utilização pelas ciências humanas, ver: BOURDIEU, P. A ilusão biográfica. In: AMADO, J.; FERREIRA, M. M. (Coord.). Usos e abusos da história oral. Rio de Janeiro: Ed. FGV, 2000. p. 183-191; POLLAK, M. Memória, esquecimento, silêncio. In: Estudos Históricos, v. 2, n. 3, p. 3-15, 1989; POLLAK, M. Memória e identidade social. In: Estudos Históricos, v. 5, n. 10, p. 200-212, 1992; HALBWACHS, M. A memória coletiva. São Paulo: Vértice, 1990.

13. ALBERTI, Verena. Manual de História Oral. Rio de Janeiro: FGV, 2004.

14. LE GOFF, Jacques. Memória In: História e memória. Campinas: Ed. Unicamp, 1994.

15. ASSMANN, Aleida. Memória funcional e memória cumulativa - Dois modos da recordação. In: Espaços de Recordação: formas e transformações de memória cultural. Editora Unicamp: Campinas, 2011.

16. NORA, Pierre. Entre Memória e História: a problemática dos lugares, In: Projeto história: Revista do programa de estudos pós-graduados em história e do departamento de história da PUC- SP. São Paulo: PUC, 1981.

17. HALBWACHS, Maurice. Memória coletiva e memória histórica In: A memória coletiva. Trad. de Beatriz Sidou. São Paulo: Centauro, 2006.

18. LE GOFF, 1994, p.427.

19. LE GOFF, 1994, p. 475.

20. ASSMANN, 2011, p. 153.

Enviado: Outubro, 2019. 
Aprovado: Janeiro, 2020. 